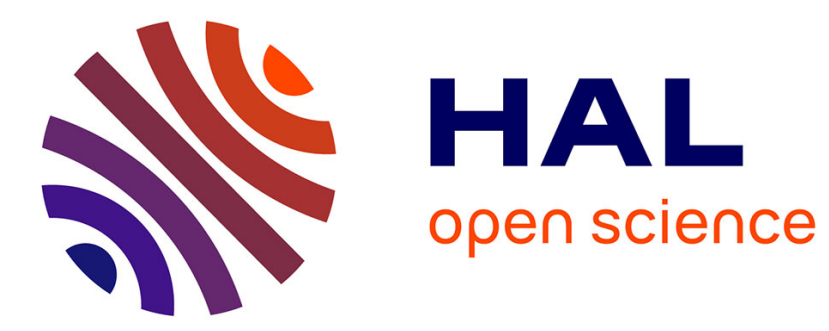

\title{
Unexpected sharp peak in thermal conductivity of carbon nanotubes water based nanofluids
}

Thierry Maré, Salma Halelfadl, Stefan van Vaerenbergh, Patrice Estellé

\section{To cite this version:}

Thierry Maré, Salma Halelfadl, Stefan van Vaerenbergh, Patrice Estellé. Unexpected sharp peak in thermal conductivity of carbon nanotubes water based nanofluids. International Communications in Heat and Mass Transfer, 2015, 66, pp.80-83. 10.1016/j.icheatmasstransfer.2015.05.013 . hal01158229

\section{HAL Id: hal-01158229 \\ https://hal.science/hal-01158229}

Submitted on 1 Jun 2015

HAL is a multi-disciplinary open access archive for the deposit and dissemination of scientific research documents, whether they are published or not. The documents may come from teaching and research institutions in France or abroad, or from public or private research centers.
L'archive ouverte pluridisciplinaire HAL, est destinée au dépôt et à la diffusion de documents scientifiques de niveau recherche, publiés ou non, émanant des établissements d'enseignement et de recherche français ou étrangers, des laboratoires publics ou privés. 


\title{
Unexpected sharp peak in thermal conductivity of carbon nanotubes water based nanofluids
}

\author{
Thierry Maré ${ }^{a}$, Salma Halelfadl ${ }^{a}$, Stefan Van Vaerenbergh ${ }^{b}$, Patrice Estellé ${ }^{c \dagger}$
}

\begin{abstract}
${ }^{a}$ LGCGM EA3913, Equipe Matériaux et Thermo-Rhéologie, Université Rennes 1, IUT de Saint-Malo, Rue de la Croix Désilles, CS51713, 35417 Saint-Malo Cedex, France.

${ }^{b}$ Chemical Physics EP, MRC CP 165-62, Université Libre de Bruxelles, 50 av. Roosevelt, 1050 Brussels, Belgium.

${ }^{c}$ LGCGM EA3913, Equipe Matériaux et Thermo-Rhéologie, Université Rennes 1, IUT de Rennes, 3 rue du Clos Courtel, BP 90422 , 35704 Rennes Cedex 7, France.

$\dagger$ Corresponding author: patrice.estelle@ univ-rennes1.fr ; Tel: +33 (0) 232342 00; Fax: +33 (0) 223234051.
\end{abstract}

The authors declare no conflict of interest.

Abstract: We report here the thermal conductivity measurement of carbon nanotubes waterbased nanofluids stabilized by sodium dodecylbenzene sulfonate as a function of volume fraction and temperature. For the first time, we further show the existence of a sharp peak in thermal conductivity at very small volume fraction below theoretical percolation threshold which is temperature independent. This preliminary study evidences the potential of promising and useful nanofluid for practical applications in cooling and energy systems and heat exchangers, as viscosity penalty is obviously vanished at this concentration.

Keywords: CNT nanofluids, Thermal conductivity, Experiments, Peak, Percolation threshold

\section{Introduction}

It is now well established that nanofluids - conventional fluids incorporating in low volume fraction nanoparticles with enhanced thermal properties - are promising candidates as heat transfer fluids in heat exchangers, cooling and energy systems. Most studies related to nanofluids have focused on the thermal performances of these suspensions investigating the effect of particle size, shape, material and concentration, temperature, nature of the base fluid, 
use of surfactant, preparation methods [1-9]. The physical mechanisms responsible of thermal conductivity enhancement were also investigated [10]. Many attempts have also be made to model and predict the enhancement of nanofluids thermal conductivity [11-17] taking into account the presence of nanoparticle aggregates [18,19] and the influence of chain-like structures [20,21]. It is usually recognized that thermal conductivity enhancement of nanofluids produces under percolation threshold, i.e. for a critical nanoparticle loading when the conductive nanoparticles start to form a continual connected network. This thermal conductivity enhancement is also mainly governed by the increase in nanoparticle volume fraction and aspect ratio of nanoparticles.

Nowadays, in addition to stability, the practical use of nanofluids remains still limited because the thermal conductivity enhancement of nanofluids is often penalized by the viscosity increase due to the addition of nanoparticles. However, nanofluid viscosity is related to resistance to flow and pumping power. This is why a tradeoff between enhanced thermal properties and reduced viscosity is needed for nanofluids. So, a simple solution to obtain useful and efficient nanofluids basically consists in dispersing a small amount of nanoparticles with high intrinsic conductivity and high aspect ratio within a low viscosity fluid.

The purpose of this short communication is to report the thermal conductivity measurement of water-based nanofluids containing carbon nanotubes stabilized by SDBS as surfactant. As an extension of our previous works [17,22-24], we study the effect of nanoparticle volume fraction and temperature on thermal conductivity, considering unusually very low volume fraction below the critical concentration of theoretical percolation threshold. Unexpectedly, we find here the existence of a very small optimal concentration leading to a peak in thermal conductivity where the enhancement is similar to the one obtained at high volume fraction.

\section{Materials and experiments}


The nanofluids used in this study were stable dispersions of MWCNT of $1.5 \mu \mathrm{m}$ in average length and $9.2 \mathrm{~nm}$ in average diameter dispersed in a mixture of de-ionized water and SDBS as surfactant. The average aspect ratio of the nanotubes is about 160 . This leads to a theoretical percolation threshold around $6.25 \times 10^{-3} \%$. This value is very low as the percolation threshold is a direct function of particle size and mainly scales with the inverse of nanoparticle aspect ratio [25,26]. As reported in [27], a starting suspension containing $1 \%$ in weight fraction of nanotubes and $2 \%$ in weight fraction of SDBS was prepared and provided by Nanocyl. The surfactant concentration was established by the manufacturer. Due to the hydrophobic surface of carbon nanotubes, the surfactant was used to disperse and stabilize the nanotubes within the suspension. Nanofluid suspensions with lower content in nanotube were obtained at ambient temperature by the dilution of the starting suspension with de-ionized water, keeping a constant weight ratio of SDBS/CNT equal to 2. Once diluted, each suspension was stirred with mechanical agitator to ensure a good dispersion of the nanotubes and reduce the possible presence of aggregates. Then, the nanofluids were stored in a container at ambient temperature before being used for thermal conductivity measurements. So, the nanoparticle volume fraction range investigated varies between $5.5 \times 10^{-4} \%$ to $0.55 \%$ at ambient temperature. The initial base fluid was also prepared by Nanocyl, and used to produce from dilution the base fluids corresponding to the different nanofluids previously prepared. It should be noted that we have previously shown that under $0.0278 \%$, the studied nanofluids behave in a Newtonian manner with a viscosity value similar to the one of de-ionized water ${ }^{23}$.

We measured the thermal conductivity of nanofluids and base fluids by using a transient hot wire (KD2 Pro thermal property analyzer equipped with KS-1 probe). As previously reported in [17,22-24], the maximum uncertainty in the thermal conductivity measurement was estimated to be less than $3.5 \%$ using distilled water as calibration liquid for temperatures range from 20 to $50^{\circ} \mathrm{C}$. Before each measurement, both the sample and the probe were maintained 30 
min at the working temperature. Then, an average of over ten measurements was performed to reduce the experimental error. The time interval of measurements was $5 \mathrm{~min}$. The thermal conductivity measurements were carried out at $20^{\circ} \mathrm{C}$.

\section{Results and discussion}

Figure 1 shows the thermal conductivity ratio of nanofluids in comparison with base fluids as a function of volume fraction of MWCNT. It is worth noting that the thermal conductivity of the base fluids decreases when the amount of surfactant increases. At the lowest concentration, the thermal conductivity ratio is quite constant up to $0.055 \%$ (within the experimental uncertainty), and in this concentration range the enhancement in thermal conductivity was not really significant (about $5 \%$ ). Above $0.055 \%$ in volume fraction, the thermal conductivity ratio increases with the volume fraction. As expected, the highest value of thermal conductivity ratio was observed for the highest tested volume fraction in nanoparticles and corresponds to an enhancement in thermal conductivity of about $26 \%$. Surprisingly, we also observed that the thermal conductivity ratio suddenly increased when the volume fraction of nanoparticles reaches a volume fraction of about $1.1 \times 10^{-3} \%$. At this concentration, the enhancement in thermal conductivity is about $13 \%$. This is similar to the enhancement in thermal conductivity for a volume fraction of $0.278 \%$.

In order to investigate the effect of temperature on thermal conductivity of the tested nanofluids, we perform another series of experiments at $46^{\circ} \mathrm{C}$. This temperature was chosen as it has been recognized that the bonding between SDBS and nanoparticles can be damaged at elevated temperature higher than $50^{\circ} \mathrm{C}$, thus limiting the stability of the nanofluids [28]. Figure 2 shows the thermal conductivity ratio of nanofluids in comparison with base fluids as a function of volume fraction of MWCNT at $46^{\circ} \mathrm{C}$. Figure 2 confirms the findings reported above, since we observe an increase in thermal conductivity ratio with the nanoparticle loading within the range $0.0055 \%$ to $0.55 \%$. The highest conductivity ratio occurs also at the highest nanotubes 
volume fraction, where enhancement in thermal conductivity is about $50 \%$. At the lowest volume fractions, the thermal conductivity enhancement is low except at about $1.1 \times 10^{-3} \%$, where a peculiar behavior is observed again. At this concentration, the enhancement in thermal conductivity is about 28\%. Finally, it is shown by both figures 1 and 2 that the thermal conductivity of nanofluids increase when the temperature is increased, as generally reported with nanofluids1.

The previous observations and results raise the following question: What is the reason for the enhancement in the thermal conductivity at particle loading of $1.1 \times 10^{-3} \%$ ? We attempt to address this question from SEM characterization of the studied nanofluids. Thus, the morphology and the dispersion state of the nanofluids was determined by scanning electron microscopy (SEM-JEOL-JSM-6301F) performed on dried nanofluid, using an accelerating voltage ranging from 7 to $10 \mathrm{kV}$ and a working distance of $8 \mathrm{~mm}$. It is worth noting that SEM characterization of the starting suspension with a volume fraction of $0.5 \%$ was previously performed, showing that at this concentration the nanotubes are mainly entangled and can form aggregates [29]. This can explain, at least partially, the substantial thermal conductivity enhancement at this particle loading. Figure 3 shows the microscopy images of CNT waterbased nanofluids taken at three different lower volume fractions of $0.278 \%, 0.0055 \%$ and $1.1 \times 10^{-3} \%$ respectively.

We can note several features from images reported in figure 3. The nanotubes appear randomly oriented with no apparent preferential directions whatever the volume fraction, and form a connected network of conducting nanotubes allowing the concept of percolation to be used. At $0.278 \%$ in volume fraction, the nanotubes are highly entangled without significant presence of agglomerates. For lower volume fraction of $0.005 \%$, figure 3 shows, as expected, that the nanotubes are better dispersed, but multiple tube-tube interactions are also observed. 
For the critical volume fraction of $1.1 \times 10^{-3} \%$, the nanotubes are interconnected with a limited number of contacts.

These results suggest that there exists a preferential spatial distribution of nanotubes probably linked to their aspect ratio where the inter-nanotubes interaction and the number of contacts are more important that the formation of a percolated network. This agrees with the results reported in [30] from numerical analysis. So, A peculiar dynamic heat conductive structural path is also formed that seems to be responsible of the great thermal conductivity enhancement at very low volume fraction in CNT.

\section{Concluding remarks}

In summary, we reported thermal conductivity measurement of water-based nanofluids containing carbon nanotubes stabilized by SDBS as surfactant as a function of volume fraction up to $0.55 \%$, considering also very small particle loading typically less than $0.055 \%$. Our results showed the thermal conductivity increase with volume fraction within the range $0.055 \%$ to $0.55 \%$, which is enhanced with temperature increase. Our findings especially showed for the first time the existence of a peak in thermal conductivity at very small volume fraction around $1.1 \times 10^{-3} \%$, e.g. below theoretical percolation threshold, which is temperature independent.

While further work is required to investigate the interplay between the peak in thermal conductivity, the size of nanotubes and the potential role of surfactant as thermal resistance and clearly understand the mechanisms responsible for such intriguing behavior, our results established that the nanofluid presently investigated can be a real candidate for heat transport applications. It obviously exhibits relative large thermal conductivity enhancement at very small volume fraction without viscosity penalty.

\section{Acknowledgements}


The authors wish to thank Nanocycl (Belgium) for preparing and providing the CNT water based nanofluid, as well as Dr J. Amadou (Nanocyl) for fruitful discussions.

\section{References}

[1] J. Philip, P.D. Shima, Thermal properties of nanofluids- A Review, Advances in Colloid and Interface Science, 2012, 183-184, 30-45.

[2] H. Xie, L. Chen, Review on the Preparation and Thermal Performances of Carbon Nanotube Contained Nanofluids, Journal of Chemical \& Engineering Data, 2011, 56(4), 1030-1041.

[3] D. Wu, H. Zhu, L. Wang, L. Liua L., Critical issues in nanofluids preparation, characterization and thermal conductivity, Current Nanoscience, 2009, 5, 103-112.

[4] T. Luo, G. Chen, Nanoscale heat transfer-from computation to experiment, Physical Chemistry Chemical Physics, 2013, 15, 3389-3412.

[5] S. Ozturk, Y.A. Hassan and V.M. Ugaz, Graphene-enhanced nanorefrigerants, Nanoscale, 2013, 5, 541-547.

[6] T.T. Baby, S. Ramaprabhu, Experimental investigation of the thermal transport properties of a carbon nanohybrid dispersed nanofluid, Nanoscale, 2011, 3, 2208-2214.

[7] A. Amrollahi, A.A. Hamidi, A.M. Rashidi, The effects of temperature, volume fraction and vibration time on the thermo-physical properties of a carbon nanotube suspension (carbon nanofluid), Nanotechnology, 2008, 19, 315701.

[8] A. Nasiri, M.S. Niasar, A. Rashidi, A. Amrollahi, R. Khodafarin, Effect of dispersion method on thermal conductivity and stability of nanofluid, Experimental Thermal and Fluid Science, 2011, 35, 717-723.

[9] A. Nasiri, M. Shariati-Niasar, A.M. Rashidi, R. Khodafarin, Effect of CNT structures on thermal conductivity and stability of nanofluid, International Journal of Heat and Mass Transfer, 2012, 55, 1529-1535.

[10] J.J. Wang, R.T. Zheng, J.W. Gao, G. Chen, Heat conduction mechanisms in nanofluids and suspensions, Nano Today, 2012, 7, 124-136.

[11] D.H. Kumar, H.E. Patel, V.R. Rajeev Kumar, T. Sundararajan, T. Pradeep, S.K. Das, Model for heat conduction in nanofluids, Physical Review Letters, 2004, 93, 144301.

[12] R. Prasher, P. Bhattacharya, P.E. Phelan, Thermal conductivity of nanoscale colloidal solutions (nanofluids), Physical Review Letter, 2005, 94, 025901. 
[13] M. Vladkov, J.L. Barrat, Modeling transient absorption and thermal conductivity in a simple nanofluid, Nano Letters, 2006, 6, 1224-1228.

[14] J. Eapen, J. Li, S. Yip, Mechanism of thermal transport in dilute nanocolloids, Physical Review Letters, 2007, 98, 028302.

[15] N.N. Venkata Sastry, A. Bhunia, T. Sundararajan, S.K. Das, Predicting the effective thermal conductivity of carbon nanotube based nanofluids, Nanotechnology, 2008, 19, 055704 .

[16] B. Lamas, B. Abreu, A. Fonseca, N. Martins, M. Oliveira, Critical analysis of the thermal conductivity models for CNT based nanofluids, International Journal of Thermal Sciences, 2014, 78, 65-76.

[17] P. Estellé, S. Halefadl, T. Maré, Thermal conductivity of CNT water based nanofluids: Experimental trends and models overview, Journal of Thermal Engineering 1(2) (2015) 381-390.

[18] R. Prasher, P.E. Phelan, P. Bhattacharya, Effect of aggregation kinetics on the thermal conductivity of nanoscale colloidal solutions (nanofluid), Nano Letters, 2006, 6, $1529-1534$.

[19] P.D. Shima, J. Philip, B. Raj, Influence of aggregation on thermal conductivity in stable and unstable nanofluids, Applied Physics Letters, 2010, 97, 153113.

[20] J. Philip, P.D. Shima, B. Raj, Enhancement of thermal conductivity in magnetite based nanofluid due to chainlike structures, Applied Physics Letters, 2007, 91, 203108.

[21] J. Philip, P.D. Shima, B. Raj, Evidence for enhanced thermal conduction through percolating structures in nanofluids, Nanotechnology, 2008, 19, 305706.

[22] Halelfadl, T. Maré, P. Estellé, Efficiency of carbon nanotubes water based nanofluids as coolants, Experimental Thermal and Fluid Science, 2014, 53, 104-110.

[23] S. Halelfadl, A.M. Adham, N. Mohd-Ghazali, T. Maré, P. Estellé, R. Ahmad, Optimization of thermal performances and pressure drop of rectangular microchannel heat sink using aqueous carbon nanotubes based nanofluid, Applied Thermal Engineering, $2014,62,492$.

[24] S. Halelfadl, P. Estellé, T. Maré, Heat transfer properties of aqueous carbon nanotubes nanofluids in coaxial heat exchanger under laminar regime, Experimental Thermal and Fluid Science, 2014, 55, 174-180.

[25]M.J. Biercuk, M.C. Llaguno, M. Radosavljevic, J.K. Hyun, A.T. Johnson, J.E. Fischer, Carbon nanotube composites for thermal management, Applied Physics Letters, 2002, 80, 2767.

[26] A.V. Kyrylyuk, M.C. Hermant, T. Schilling, B. Klumperman, C.E. Koning, P. van der Choot, Controlling electrical percolation in multicomponent carbon nanotube dispersions, Nature Nanotechnology, 2011, 6, 364-369.

[27] S. Halelfadl, P. Estellé, B. Aladag, N. Doner, T. Maré, Viscosity of carbon nanotubes water-based nanofluids: Influence of concentration and temperature, International Journal of Thermal Sciences, 2013, 71, 111. 
[28] L. Vaisman, H.D. Wagner, G. Marom, The role of surfactants in dispersion of carbon nanotubes, Advances in Colloid and Interface Science, 2006, 128-130, 37-46.

[29] P. Estellé, S. Halelfadl, N. Doner, T. Maré, Shear history effect on the viscosity of carbon nanotubes water-based nanofluid, Current Nanoscience, 2013, 9, 225-230.

[30] B. Lamas, B. Abreu, A. Fonseca, N. Martin, M. Oliveira, Numerical analysis of percolation formation in carbon nanotube based nanofluids, International Journal for Numerical Methods in Engineering, 2013, 95, 257-270. 


\section{Figures Captions}

Fig. 1. Relative thermal conductivity of nanofluids at $20^{\circ} \mathrm{C}$ as a function of volume fraction in nanoparticle.

Fig. 2. Relative thermal conductivity of nanofluids at $46^{\circ} \mathrm{C}$ as a function of volume fraction in nanoparticle.

Fig. 3. SEM pictures taken from dried nanofluids with various volume fractions in CNT, from top to bottom $0.278 \%, 0.0055 \%$ and $1.1 \times 10^{-3} \%$. 


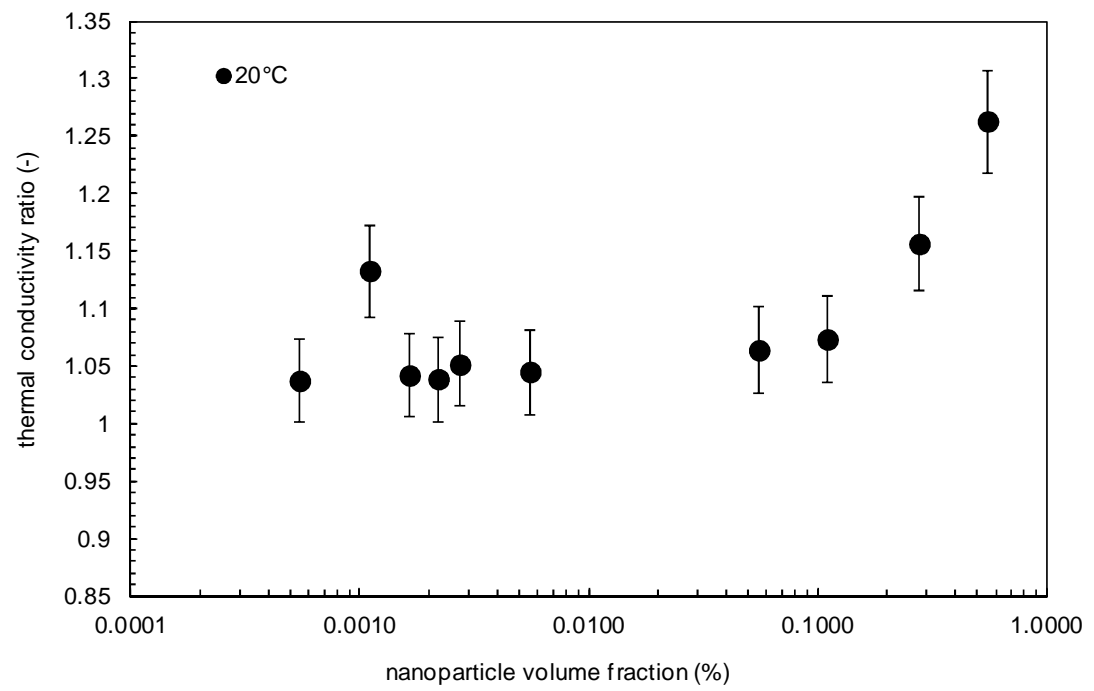

Fig. 1. Relative thermal conductivity of nanofluids at $20^{\circ} \mathrm{C}$ as a function of volume fraction in nanoparticle. 


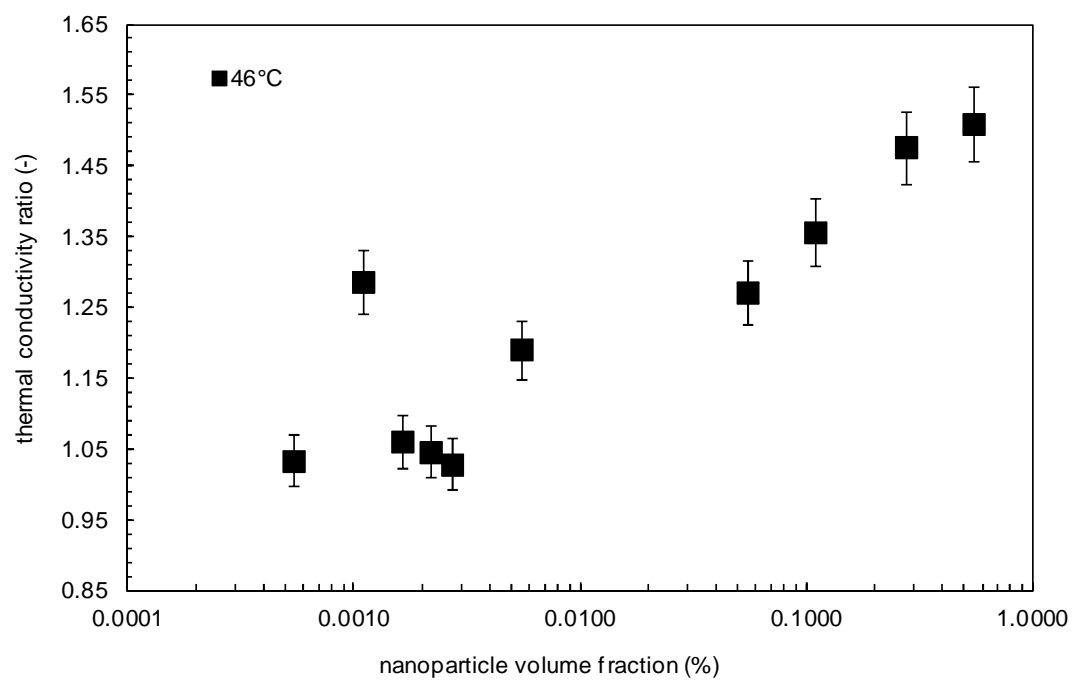

Fig. 2. Relative thermal conductivity of nanofluids at $46^{\circ} \mathrm{C}$ as a function of volume fraction in nanoparticle. 

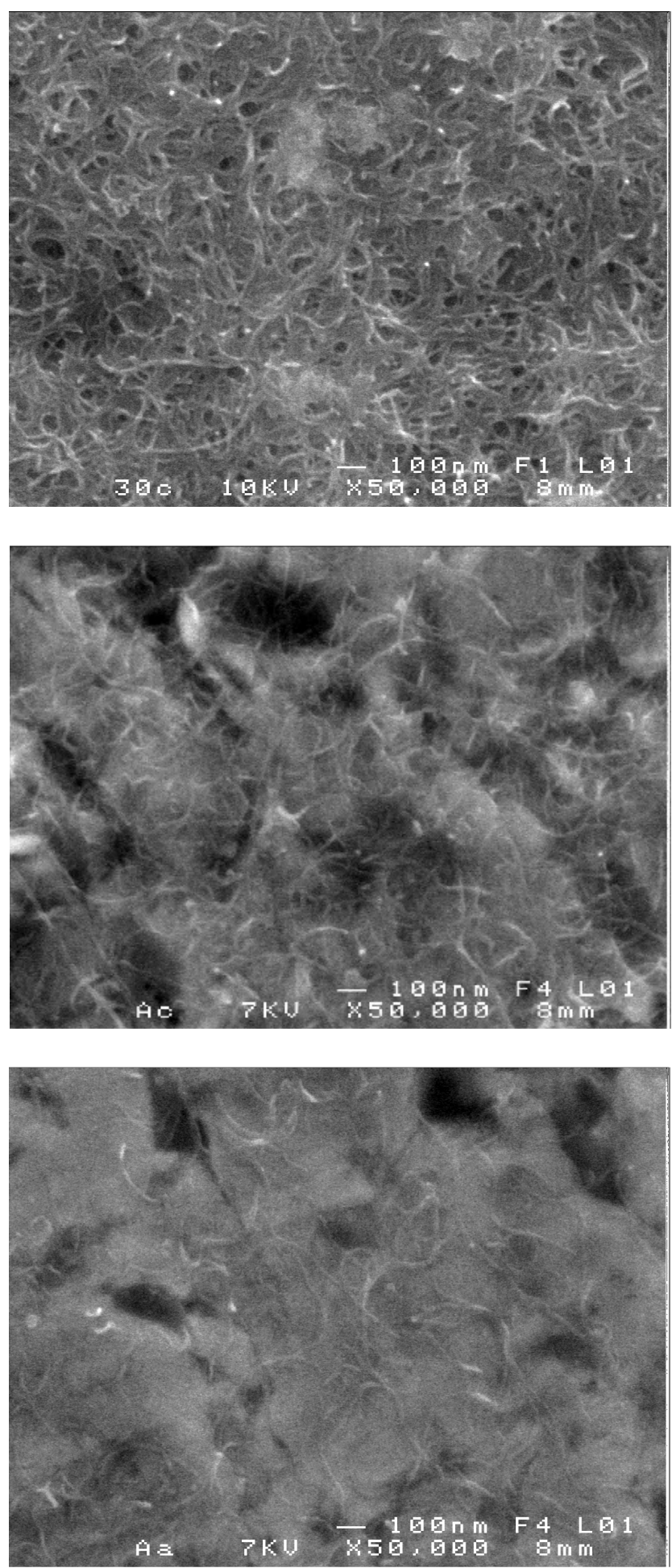

Fig. 3. SEM pictures taken from dried nanofluids with various volume fractions in CNT, from top to bottom $0.278 \%, 0.0055 \%$ and $1.1 \times 10^{-3} \%$. 